me with her; we both hope it stays that way for a long, long time. There are many challenges however, and also opportunities in this newest phase of our marriage and personal lives. A gifted, tough-minded, but warm psychologist overseeing 4 mental health clinics in British Columbia, she has been forced to shut down her own clinical practice. A large part of her identity centred around her work, with the many clients that she has helped over the years and the associated rewards of appreciation from those she has helped, and of knowing that she has provided quality psychotherapy and that at the end of the day she has indeed made a difference.
As for me, I have learned that I can make 2 types of mistakes in our daily to-and-fro and give-and-take. The first kind is the anxious husband reaching out to help his wife when she neither needs nor wants assistance. The second type of error sees me missing an opportunity to help her when she genuinely needs it. Type 1 errors are more common and really tee her off. Type 2 errors are mercifully less frequent, or so she says.

I comfort her when she's having a bad day, feeling irritated or frustrated. And sometimes I feel cheered up myself, reassured and relieved in being able to be there for her. Most days we enjoy each other and, sometimes, hugely. Laughing. Fight- ing. Making up. Making love. Teasing and joking. Snuggling. Tasting her superb rhubarb crisp. So just as in the time before Alzheimer disease came into our lives, on our very best days we live contentedly in the moment, in the here-and-now.

After all, isn't that what any of us would do on a good day when we're with those who count - our family and friends? Alzheimer disease is just an unkind, uninvited stranger in our midst. But we don't have to wait until it comes rudely visiting before we enjoy our wife or husband or partner, other family or friends, before we appreciate — and acknowledge — how much they mean to us.

My grandmother said it better than ever I could have. "Make hay while the sun shines!" she would remind me today.

\section{David Kirkpatrick MA MD}

Psychiatrist and psychotherapist West Vancouver, BC

\title{
Past progressive
}

\section{The glorification of gout in 16th- to 18th-century literature}

$\mathrm{L}$ iterary references to gout are a prime example of the insight into popular perceptions of disease that historical writings offer. While praise of podagra is currently in short supply, the merits of gout have been extolled over the centuries by physicians and laypersons. In the past, gout was regarded as a badge of nobility, a talisman against other afflictions and an aphrodisiac, and these beliefs were preserved in 16th- to 18 th-century literature.

\section{A mark of nobility}

Gout as a disease of the nobility was referred to and explained in a popular fable involving Mr. Gout and the spider. This story has been traced to the ninth century, ${ }^{1}$ and the first English version of it was recorded in a medical handbook by the Puritan Richard Hawes in $1634 .^{2}$
The tale tells of Monsieur Gout and his travelling companion, the spider. Mr. Gout lodged with a poor man, and the spider with a rich man. When they reviewed their accommodations the next day, both had complaints.

“"Mine,' said the Gout, 'was the worst as ever I had, for I had no sooner touched the poor man's legs, thinking there to take my rest, but up he gets, and to thrashing he goes, so that I had no rest the whole night.'

'And I,' said the spider, 'had no sooner begun to build my house in the rich man's chamber, but the maid came with a broom, and tore down all my work." ${ }^{3}$

They then agreed to change places and were so pleased with their respective new homes that they each decided to put up permanent residence, for the spider's webs were not disturbed by the poor man, and "the Gout he was enter- tained with a soft cushion, with down pillows, with dainty caudles, and delicate broths. In brief, he did like it so well, that ever since he takes up his lodging with rich men." ${ }^{3}$

This fable purports to explain gout's apparent predilection for the upper class. Gout was referred to as morbus dominorum et dominus morborum, lord of disease and disease of lords,,${ }^{4,5}$ because of its respectable antiquity and its association with intemperance afforded only by the wealthy. Gout was personified as one of the Greek deities, Podagra, born of Dionysus (Bacchus), the god of wine, and Aphrodite (Venus), the goddess of love. ${ }^{5-7}$ The idea that gout resulted from service to these gods and was a consequence of overindulgence in sex, food and wine was recorded by ancient Roman authors and persisted into the Christian era. ${ }^{6-8}$ 


\section{A good-luck piece}

Another popular idea of 16th- to 18thcentury Europe was that gout was a remedy rather than a disease. Jonathan Swift (1667-1745), the Irish author and satirist, articulates this concept in his poem for his acquaintance Rebecca Dingley entitled "Bec's Birthday" (1726).

As, if the gout should seize the head, Doctors pronounce the patient dead; But, if they can, by all their arts,

Eject it to th'extreamest parts,

They give the sick man joy, and praise The gout that will prolong his days:

Rebecca thus I gladly greet,

Who drives her cares to hands and feet. ${ }^{9}$

Gout was understood to be incompatible with most other afflictions, in keeping with the age-old idea that diseases were mutually exclusive. As such, gout was regarded as a cure, a vaccine, an insurance policy against worse illness. ${ }^{5}$ In his letters, the English writer Horace Walpole claimed, "It prevents other illness and prolongs life. Could I cure the gout, should not I have a fever, a palsy or an apoplexy?" ${ }^{5} \mathrm{He}$ went on, "I believe the gout a remedy and not a disease, and being so no wonder there is no medicine for it, nor do I desire to be fully cured of a remedy."

Gout was sought by some who did not have it. In the 18th century, patients suffering from consumption or melancholy were sent by their physicians to the waters at Bath in the hope of acquiring gout and so ousting their other sickness. ${ }^{5,10}$

\section{Podagra as an aphrodisiac}

Gout was also touted as having aphrodisiac properties. The earliest reference to gout as an aphrodisiac is the Podagra Encomium of 1562 by Hieronymus Cardanus of Pavia (1501-1576)." A physician and mathematician, Cardanus explained in his encomium, a formal yet facetious expression of praise, that: "For with Venus and Bacchus and the feasts of voluptuaries an abiding covenant serves as check, and such a cause of happiness is she [the gout] that those who are restrained by her are compelled to lead lives that, except for the pain itself are happy. For

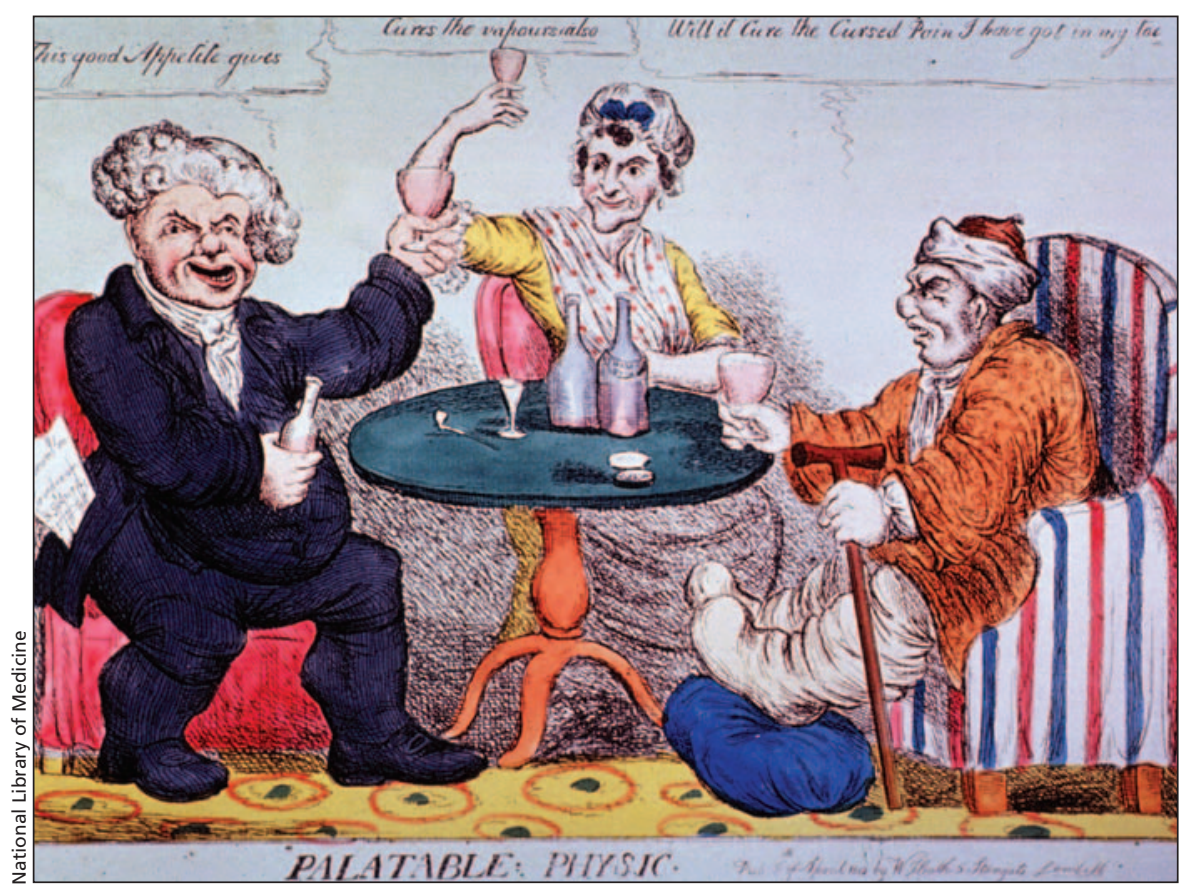

she does not render them sterile but restores them to Venus with increased prowess." 11

T.G. Benedek reviews several reasons that were postulated for this sexual performance-enhancing character of gout. ${ }^{11}$ In his 1588 essay, "Of Cripples," Michel de Montaigne, the French Renaissance writer, explains that when the legs are crippled (by any cause) and "do not receive the food that is their due ... the genital parts ... are fuller, better nourished, and more vigorous. or else that, since this defect prevents exercise, those who are tainted by it dissipate their strength less and come more entire to the sports of Venus." "11

In 1693, Gerhardus Feltmann, a 17th-century Dutch jurist, suggested that the sexual prowess of a person suffering with gout was due to the incubating effect of bed rest on the reproductive organs: "For when a patient who is suffering from gout is forced to lie on his back, anyone who knows that the channels of the sperm trace their source to the kidneys can easily and at his leisure comprehend that the loins and kidneys are hot and inflamed."

Historical conceptions of gout may be entertaining and the current metabolic definition of the disease considered a scientific advancement, however, if I were to diagnose gout in a patient today, I would prefer to temper the announcement with the reassurance that the condition guaranteed increased social status, a reduction of cancer risk, and an end to Viagra refills.

\section{Martina Scholtens MD}

John Ruedy Immunodeficiency Clinic

St. Paul's Hospital

Bridge Community Health Clinic

Vancouver Coastal Health

Vancouver, BC

\section{REFERENCES}

1. Rodnan GP, Benedek TG. Gout and the spider. JAMA 1970;211:2157.

2. Benedek TG. Popular literature on gout in the 16th and 17th centuries. J Rheumatol 1987;14:186.

3. Eamon W. The tale of monsieur gout. Bull Hist Med 1981:55:564-7.

4. Hart FD. Gout and non-gout through the ages. $\mathrm{Br} J$ Clin Pract 1985;39:91-2.

5. Porter R. Gout: framing and fantasizing disease. Bull Hist Med 1994;68:1-28.

6. Rodnan GP. Early theories concerning etiology and pathogenesis of the gout. Arthritis Rheum 1965;8:599-610.

7. Benedek TG. The gout of Desiderius Erasmus and Willibald Pirckheimer: medical autobiography and its literary reflections. Bull Hist Med 1983;57:52644.

8. Benedek TG, Rodnan GP. Podagra by Gottfried Rogg: an illustrated encomium on the gout. J Hist Medicine Allied Sci 1963;18:349-52.

9. Swift J. Bec's Birthday. In: Williams H, editor. The poems of Jonathan Swift. 2nd ed. Oxford (UK): Clarendon Press; 1937. p.761.

10. Copeman WSC. A short history of the gout and the rheumatic diseases. Berkeley and Los Angeles: University of California Press; 1964.

11. Benedek TG. Disease as aphrodisiac. Bull Hist Med 1971;4:322-40. 